\title{
Diagnosis of a right coronary artery-left ventricular fistula by cross sectional and Doppler echocardiography
}

\author{
YONGYUTH SAHASAKUL, * SUPHACHAI CHAITHIRAPHAN, * \\ SOMCHAI SRIYOSCHATI $\dagger$ \\ From the ${ }^{\star}$ Division of Cardiology, Department of Medicine, and the $\dagger$ Division of Cardiothoracic Surgery, \\ Department of Surgery, Faculty of Medicine, Siriraj Hospital, Mahidol University, Bangkok, Thailand
}

SUMMARY A case of right coronary to left ventricular fistula was diagnosed by cross sectional and Doppler echocardiography. The origin and site of entry into the left ventricle of the enlarged right coronary artery were shown by cross sectional echocardiography. Diastolic flow was detected in the left ventricle by both pulsed and continuous Doppler echocardiography. The fistula was confirmed by cardiac catheterisation and was successfully closed at operation.

Coronary artery fistula is a rare congenital anomaly in which the affected coronary artery empties into the left ventricle. ${ }^{1-3}$ These fistulas can be identified by angiography but recent reports have shown the potential usefulness of non-invasive techniques. ${ }^{46}$ We report a case in which a combination of cross sectional and pulsed and continuous Doppler echocardiography was used to image a coronary artery fistula and identify its site of drainage.

\section{Case report}

A 23 year old woman had a two year history of exertional dyspnoea, palpitation, and recurrent dizziness. Physical examination showed a normally developed young woman. Blood pressure was 140/90 $\mathrm{mm} \mathrm{Hg}$ in both arms, and the pulse was 88 beats per minute and regular. There was no clinical evidence of cardiac enlargement. The first and second heart sounds were normal in quality and intensity. There was a grade $3 / 6$ diastolic murmur over the central lower region of the sternum. The electrocardiogram showed left ventricular hypertrophy by voltage criteria. A chest $x$ ray showed slight cardiomegaly with a circumscribed opaque round shadow at the right cardiophrenic angle (fig 1a).

Requests for reprints to Dr Yongyuth Sahasakul, Division of Cardiology, Department of Medicine, Siriraj Hospital, Mahidol University, Bangkok 10700, Thailand.
At cardiac catheterisation the left ventricular end diastolic pressure was raised at $21 \mathrm{~mm} \mathrm{Hg}$. Coronary angiography showed a considerably dilated and tortuous right coronary artery (corresponding to the right paracardiac shadow) draining into the left ventricle (fig $1 \mathrm{~b}$ ). The left coronary artery was normal.

\section{ECHOCARDIOGRAPHIC FINDINGS}

We used an Aloka mechanical scanner Model SSD118 for cross sectional echocardiography and a Toshiba phased array scanner SSH-40A for combined cross sectional and Doppler echocardiography. In the parasternal short axis view, the ostium of the right coronary artery $(2 \mathrm{~cm}$ in diameter) was seen to originate from the aorta (fig 2a). The site of entry $(1 \mathrm{~cm}$ in diameter) into the moderately enlarged left ventricle was shown just below the posterior mitral leaflet at the posteromedial region of the left ventricle in a parasternal short axis view (fig 2b). This corresponded with the angiographic findings. Both pulsed and continuous Doppler showed a diastolic flow pattern at the site of entry.

At operation, a dilated right coronary artery measuring $1.5 \mathrm{~cm}$ in diameter was found communicating with the inferior wall of the left ventricular cavity at the crux. The fistula was closed at its distal end by interrupted sutures. The patient was discharged in good condition on the seventh day after surgery and was free of symptoms at follow up six months later. 


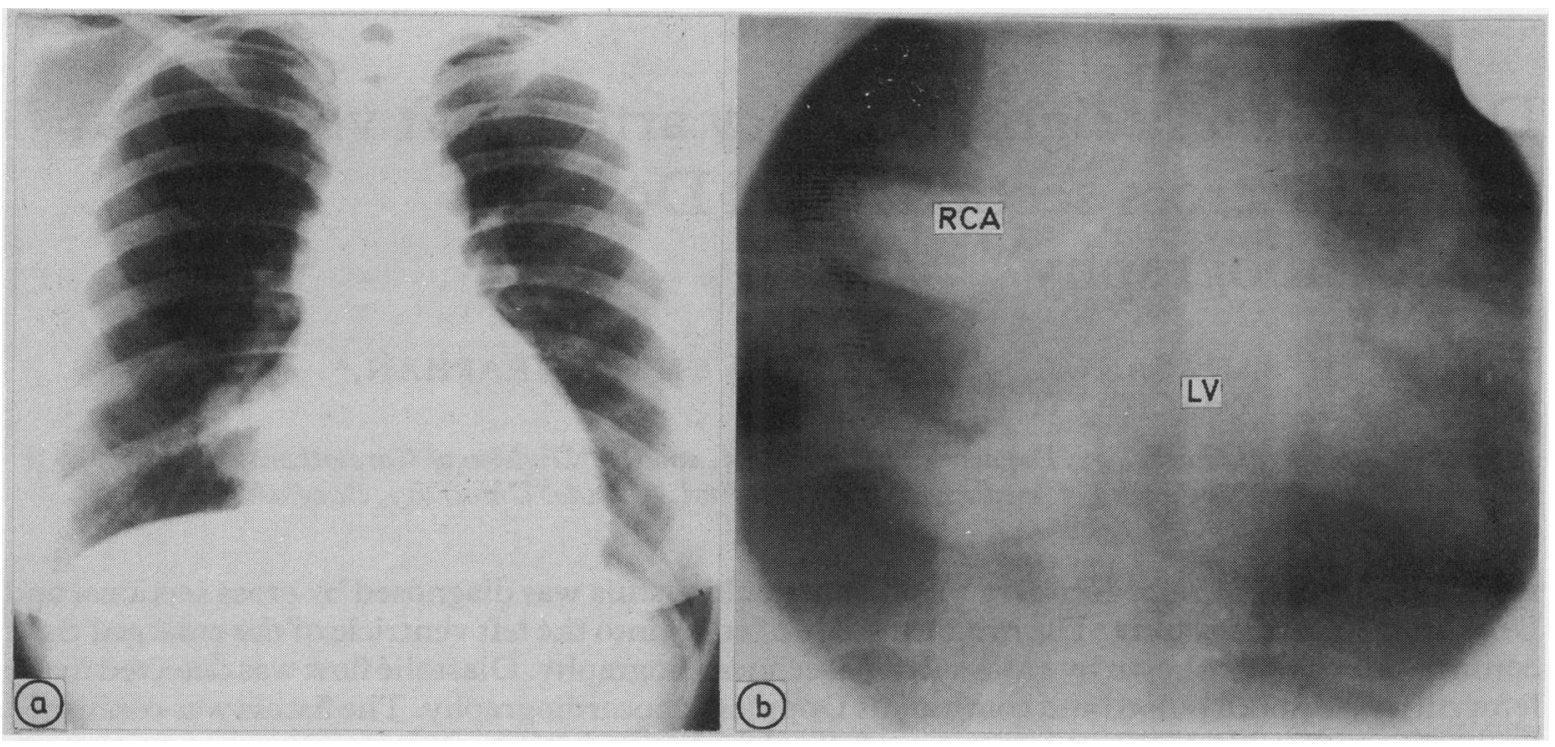

Fig 1 (a) Chest $x$ ray in posteroanterior projection showing mild cardiomegaly and normal pulmonary vasculature. There was an opaque shadow at the right cardiophrenic angle. (b) Right coronary angiogram showing a diffusely dilated, tortuous right coronary artery $(R C A)$ that emptied into the left ventricle $(L V)$.

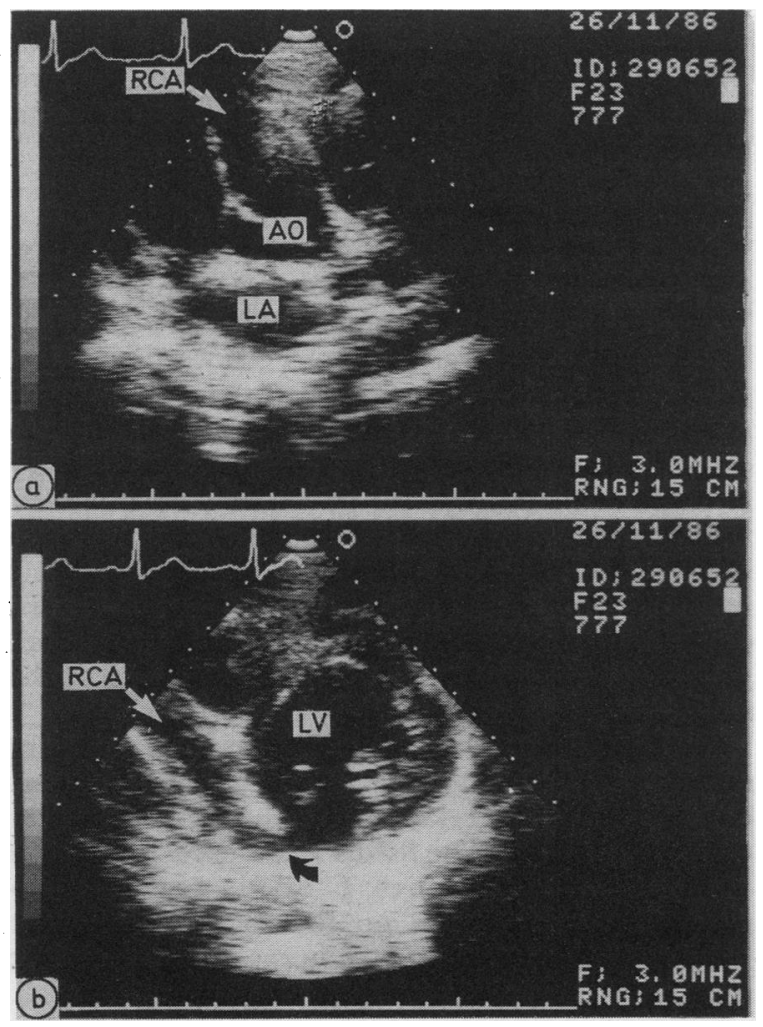

\section{Discussion}

Cross sectional echocardiography has been used to image normal calibre coronary arteries and to demonstrate dilated coronary arteries associated with the mucocutaneous lymph node syndrome and with coronary artery fistulas. ${ }^{7-9}$ Reeder et al used cross sectional echocardiography to visualise an aneurysmal coronary artery fistula and they concluded that contrast echocardiography was better than angiography for delineating the cardiac chamber into which the fistula emptied. ${ }^{4}$ The identification of both distal and proximal portions of a coronary fistula by cross sectional echocardiography has also been reported. ${ }^{410}$ Agatston et al used pulsed Doppler to confirm the site of the distal end of the fistula at the junction of the coronary sinus and right atrium. ${ }^{11}$ Cross sectional visualisation of dilated proximal coronary arteries alone, however, does not indicate the presence of a coronary fistula. ${ }^{5}$ It is often difficult to distinguish

Fig 2 Cross sectional echocardiogram showing (a) parasternal short axis view of the aorta ( $A O)$ at the level of aortic valve showing the markedly enlarged proximal right coronary artery ( $R C A$ ) (arrow); (b) parasternal short axis view just below the mitral valve showing the distal right coronary artery (white arrow) draining into the left ventricle (LV). The site of entry into the left ventricle is indicated by the curved black arrow. 
between fistulas and aneurysms of the coronary artery or anomalous origin of the coronary arteries. But Doppler echocardiography can identify continuous flow in the right heart chambers or diastolic flow in the left ventricle, and hence confirm the site of drainage of the fistula. ${ }^{112}$

Echocardiographic imaging of the dilated proximal portion and the distal end of the right coronary artery draining into the left ventricle just below the posterior mitral leaflet in this present case should therefore be sufficient for the diagnosis of a right coronary artery fistula to left ventricle. The portal of entry was detected by pulsed Doppler echocardiography and was confirmed by angiography and at operation.

\section{References}

1 Galioto FM, Reitman MJ, Slovis AJ, et al. Right coronary artery to left ventricular fistula: a case report and discussion. Am Heart J 1971;82:93-7.

2 Eguchi S, Nitta H, Asano K, et al. Congenital fistula of the right coronary artery to the left ventricle. The third case in the literature. Am Heart J 1970;80:242-6.

3 Sahasakul Y, Chaithiraphan S, Prachuabmoh K. Congenital fistula of the right coronary artery to the left ventricle: report of a case. J Med Assoc Thai 1984;67:442-7.

4 Reeder OS, Tajik AJ, Smith HC. Visualization of coronary artery fistula by two-dimensional echocardiography. Mayo Clin Proc 1980;55:185-9.
5 Yoshikawa J, Katao H, Yanaglhara K, et al. Noninvasive visualization of the main coronary arteries in coronary artery fistulas by cross-sectional echocardiography. Circulation 1982;65:600-3.

6 Cooper MJ, Bernstein D, Silverman NH. Recognition of left coronary artery fistula to the left and right ventricles by contrast echocardiography. J Am Coll Cardiol 1985;6:923-6.

7 Kronzon L, Winer HE, Cohen B. Noninvasive diagnosis of left coronary arteriovenous fistula communicating with the right ventricle. $A m$ J Cardiol 1982;49:1811-3.

8 Capannari TE, Daniels SR, Meyer RA, Schwartz DC, Kaplan S. Sensitivity, specificity and predictive value of two-dimensional echocardiography in detecting coronary artery aneurysms in patients with Kawasaki disease. J Am Coll Cardiol 1986;7:355-60.

9 Rodgers DM, Wolf NM, Barrett MJ, Zuckerman GC, Meister SG. Two-dimensional echocardiographic features of coronary arteriovenous fistula. Am Heart J 1982;104:872-4.

10 Knippel M, Ravizza P, Gullace G, et al. An unusual case of congenital double coronary arteriovenous fistula. Chest 1982;81:382-4.

11 Agatston AS, Chapman E, Hildner FJ, Samet P. Diagnosis of a right coronary artery-right atrial fistula using two-dimensional and Doppler echocardiography. Am J Cardiol 1984;54:238-9.

12 Slater J, Lighty GW Jr, Winer HE, Kahn ML, Kronzon I, Isom OW. Doppler echocardiography and computed tomography in diagnosis of left coronary arteriovenous fistula. J Am Coll Cardiol 1984;4: 1290-3. 